\title{
Gender Differences in Anxiety and Depression before and after Alcohol Detoxification: Anxiety and Depression as Gender-Related Predictors of Relapse
}

\author{
Francesco Oliva $^{a}$ Gabriele Nibbio $^{a}$ Paola Vizzuso $^{b}$ Alessandro Jaretti Sodano $^{b}$ \\ Luca Ostacolia Sara Carletto $^{a}$ Rocco Luigi Piccia

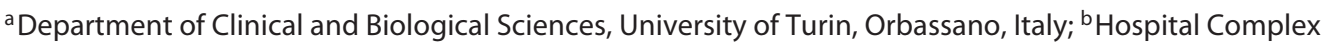 \\ "Fatebenefratelli," San Maurizio Canavese, Italy
}

\section{Keywords}

Anxiety - Depression - Alcohol use disorder - Detoxification · Relapse $\cdot$ Predictor

\section{Abstract}

Background/Aims: The aim of this prospective study was to estimate gender differences in anxiety, depression, and alcohol use severity among patients with alcohol use disorder (AUD) before and after detoxification program and within 12 months after discharge. Methods: AUD severity, state and trait anxiety, and depression were assessed in 187 patients entering an inpatient alcohol detoxification program. Follow-up assessments were performed at 6 and 12 months after discharge. A between- and within-subjects analyses explored gender differences. The predictive value of anxiety and depression for alcohol relapse was analyzed by logistic and linear regression in both genders. Results: Females had higher levels of anxiety and depression than males both at admission and after discharge. Trait anxiety and depression significantly increased 6 months after discharge in males and females respectively. Both state and trait anxiety levels at the 6-month follow-up predicted alcohol relapse at the 12-month follow-up in males. Conversely, in females, depression level at the 6-month follow-up was a predictor of relapse at the 12-month follow-up. Conclusions: In both genders, the psychopathological dimension that showed the most significant worsening at 6-month follow-up (i.e., anxiety in males and depression in females) was found to be a significant predictor of relapse at the 12-month follow-up.

(C) 2018 The Author(s)

Published by S. Karger AG, Basel

\section{Introduction}

Alcohol use disorder (AUD) is a maladaptive pattern of alcohol use, leading to clinically significant impairment or distress [1]. In the last 20 years, epidemiological studies, such as the Epidemiologic Catchment Area and National Epidemiologic Survey on Alcohol and Related Conditions, have reported a high lifetime prevalence of psychiatric disorders among patients with AUD ranging from 38 to $39.5 \%$ [2,3]. Anxiety and depressive disorders have been shown to be more prevalent in AUD patients in both epidemiological surveys [2-9] and clinical trials

\begin{tabular}{ll}
\hline KARGER & $\begin{array}{l}\text { C } 2018 \text { The Author(s) } \\
\text { Published by S. Karger AG, Basel }\end{array}$ \\
E-Mail karger@karger.com & This article is licensed under the Creative Commons Attribution- \\
www.karger.com/ear & $\begin{array}{l}\text { NonCommercial-NoDerivatives 4.0 International License (CC BY- } \\
\text { NC-ND) (http://www.karger.com/Services/OpenAccessLicense). } \\
\text { Usage and distribution for commercial purposes as well as any dis- } \\
\text { tribution of modified material requires written permission. }\end{array}$
\end{tabular}

Francesco Oliva

Department of Clinical and Biological Sciences

University of Turin, Regione Gonzole 10

IT-10043 Orbassano (Italy)

E-Mail francesco.oliva@ unito.it 
[10-12]. Indeed, anxiety and depressive disorders are associated with a greater risk of relapse following alcohol detoxification (OR 4.4, 95\% CI 1.8-10.1 for anxiety disorders and OR 2.1, 95\% CI 1.3-3.4 for depressive disorders of relapse at 1 year) $[13,14]$.

Many important differences between males and females have emerged regarding alcohol drinking behaviors and patterns, related to both biological (sex-related) and psycho-socio-cultural (gender-related) factors [15]. Depressive symptoms appear to be implicated in the development of AUD in women and to impact the frequency of high-risk drinking situations [16]. Gender differences in alcohol relapse have been correlated with different mood states [17]. The association between gender differences in depressive symptoms and risk of relapse was assessed in a retrospective study, where the burden of symptoms in women was found to correlate with an increased risk of relapse [18]. Moreover, females with AUD showed to be more prone to drink in negative emotional situations than males, although this does not seem to be related to the presence of depressive or anxiety disorders [19]. A recent prospective observational study focusing on gender differences during alcohol detoxification found a correlation between negative affect and craving, especially in women [20]. However, to the best of our knowledge, there have been no prospective studies on gender differences in anxiety and depression levels before versus after alcohol detoxification.

The aims of this study were to evaluate gender differences in trait and state anxiety and depression at admission, at discharge, and within 12 months following alcohol detoxification, and to determine whether levels of anxiety/depression could be used as gender-specific factors to predict the likelihood of relapse and the severity of alcohol use within 12 months after detoxification.

\section{Methods}

\section{Sample and Enrolment}

A consecutive sample of patients admitted for inpatient alcohol detoxification treatment was recruited at the Hospital Complex "Fatebenefratelli" in San Maurizio Canavese (Turin, Italy) between September 1, 2013 and December 1, 2014. According to the hospital regulation, the admission is allowed to adult patients (at least 18 years old) referred and diagnosed with Diagnostic and Statistical Manual of Mental Disorders, 4rd ed., text rev. DSM-IV-TR AUD (i.e., both alcohol abuse and alcohol dependence) by a territorial addiction outpatient service ("Servizio per le dipendenze patologiche") specialist (i.e., psychiatrist or MD trained in addictive medicine), who must also exclude a diagnosis of any DSM-IVTR substance use disorder. Moreover, all patients were screened by urinalysis prior to admission to exclude substance use (i.e., Cannabis, Cocaine, Opiates, Amphetamines, Methamphetamines, Barbiturates, Benzodiazepines, Buprenorphine, Methadone). The inclusion and exclusion criteria for participating in the study were consistent with criteria applicable for those who were ready for hospital admission.

The research protocol was not submitted to local Ethics Committee because, according to Italian Law, the approval was requested only for experimental and observational studies on pharmacological treatments. Nevertheless, patients were provided with comprehensive information regarding the aims, methods, risks, and benefits of the study. All patients signing a written informed consent form received a unique identification code in order to maintain data anonymity and patient confidentiality. All precautions were taken for the management of sensitive data, and participants were not given monetary compensation for their involvement.

\section{Alcohol Detoxification Program}

All patients admitted to the hospital stopped drinking alcohol. Detoxification treatment was based on a classical 1-week fixedschedule regimen $[21,22]$. During hospitalization, other psychopharmacological treatments were administered according to the evidence-based recommendations described in the American Psychiatric Association Practice Guidelines [23]. Several nonpharmacological treatments, such as parent-training intervention, short-term individual psychotherapy, group psychotherapy, motivational enhancement therapy, and nutrition education, were included at the discretion of the clinician. In accordance with the observational study design, the investigators were not actively engaged in providing treatment. All additional therapeutic interventions were recorded as dichotomous variables in the study database.

\section{Study Design}

The longitudinal design of the observational study consisted of 4 stages of observation and assessment: baseline assessment (T0); discharge assessment (T1); first follow-up at 6 months after discharge (T2); and second follow-up at 12 months after discharge (T3). The T0 assessment was made on the seventh day of hospitalization and involved the collection of both sociodemographic information (date of birth, gender, marital status, education, living conditions, and employment) and alcohol intake-related data (age at onset of alcohol use, age at onset of alcohol abuse, previous admission(s) for detoxification, and current pharmacological treatment), and the administration of assessment tools. The severity of alcohol use was evaluated using the AUDs Identification Test (AUDIT) [24]. Baseline psychopathology was estimated using the State-Trait Anxiety Inventory - Form Y (STAI-Y) [25] and the Beck Depression Inventory (BDI) [26]. At discharge, only anxiety and depression were assessed using STAI-Y and BDI. All followups included the assessment of alcohol use severity, state/trait anxiety, and depression by AUDIT, STAI-Y, and BDI respectively. From the patient's perspective, failure to sign the written informed consent form or to attend the follow-up appointments was considered refusal. In order to plan the follow-up controls, patients were asked to contact the hospital 1 week before follow-ups expiration dates by letter and e-mail, and they were also called by phone twice/week during 2 weeks after follow-ups expiration dates. $\mathrm{Pa}$ tients who could no longer be contacted at T1 and T2 were considered lost to follow-up. 


\section{Assessment Tools}

The AUDIT consists of a 10-item core questionnaire that according to the manual should be administered after the clinical screening procedure is completed. Total score ranges from 0 to 40 , is questionnaire-based only, and gives a reliable estimate of the severity of alcohol use in the preceding year [27]. In addition to alcohol dependence, this tool explores the risk of alcohol intake-related physical/mental harm arising from hazardous or harmful drinking conduct. The international and Italian versions of this tool have both been verified for their good psychometric properties $[28,29]$. In accordance with the AUDIT manual, 3 threshold values were used to identify 4 zones of risk and intervention. In the present study, patients with a score on the first item of 0 were considered abstinent; thus, all patients with scores above 0 on first item at follow-up were considered relapsed. Moreover, since the study design included a 6-month scheduled follow-up, the time reference of the questionnaire was reduced from 12 to 6 months.

STAI-Y and BDI were used to achieve continuous measurement of anxiety and depression symptoms respectively. The STAI-Y inventory consists of 40 items and is specifically designed to assess both trait and state anxiety. STAI-Y has been proven to have good psychometric properties for assessing patients with AUD (internal reliability, $\alpha=0.86-0.95)[25,30]$. The total score for each type of anxiety ranges from 20 to 80, with higher scores suggesting greater levels of anxiety. The STAI-Y has been translated and validated in its Italian version [31]. Similarly, the BDI index is a well-established 21-item tool for the quantitative assessment of depressive symptoms and is widely used in psychological research [32]. It has good psychometric proprieties, with an internal consistency that is good to excellent ( $\alpha=0.83-0.96$; [33]) and it has been translated and validated in Italian language [34]. Many studies have concluded that the BDI is a rational choice of screening tool for depression in an AUD population [35, 36].

\section{Statistical Analysis}

All computations were performed using the IBM SPSS Statistics for MACOS package version 22.0 (IBM Corporation, Armonk, NY, USA).

Gender comparison of baseline data was performed using the Pearson's $\chi^{2}$ test or Fisher's exact test for categorical variables, depending on the expected frequencies in each group. Mean differences in continuous variables were evaluated using the independent samples $t$ test or the Mann-Whitney $U$ test, depending on whether the distribution of variables was normal or non-normal, as determined by the Shapiro-Wilk test.

A generalized linear model for repeated measures was applied to analyze gender differences in longitudinal variations of state anxiety, trait anxiety, and depression. This model consists of both multivariate and univariate analyses of variance. STAI-Y and BDI scores at the 4 assessment stages (T0, T1, T2, T3) were used as the within-subject variables, and gender was used as the between-subject factor. The effect sizes of both within- and between-subject factors obtained by variance analysis are reported as a partial Etasquared $\left(\eta_{p}^{2}\right)$ value. The Huyny-Feldt epsilon correction for degrees of freedom was applied when the sphericity assumption was not met for the main effects of state anxiety, trait anxiety, depression, and alcohol use severity. Pairwise comparisons of mean scores at different stages of assessment were made by repeated contrasts (T0 vs. T1, T1 vs. T2, T2 vs. T3, and T3 vs. T0) and are reported as mean differences with a Sidak-corrected 95\% CI.

Anxiety, Depression, Alcohol

Detoxification
Logistic and linear regression analyses were also performed to evaluate the predictive value of anxiety and depression for relapse and for alcohol use severity respectively. Two logistic regression models were carried out for each gender, using relapse (yes/no) at $\mathrm{T} 2$ and $\mathrm{T} 3$ as a dichotomous outcome. Two linear regression models for each gender were instead applied to relapsed patients only, using AUDIT scores as a continuous outcome. Both logistic and linear models concerning T2 outcomes were calculated using STAY-S, STAY-T, and BDI scores at both T0 and T1 and AUDIT scores at T0 as independent variables. All models regarding T3 outcomes also included STAY-S, STAY-T, BDI, and AUDIT scores at T2. Baseline sociodemographic, alcohol intake-related, and treatment variables were initially compared by univariate analysis. Subsequently, those that were significantly different between abstinent and relapsed subjects were used as covariates in both logistic and linear regression models. Probability tests were considered bilateral with a type I error set at 5\% $(p=0.05)$.

\section{Results}

The enrolled sample consisted of 187 patients, of whom 146 attended both the 6- and 12-month follow-up appointments. All patients had a negative admission drug urine test and accepted to participate in the study, giving written informed consent; thus, no patient was excluded from the study.

A total of 41 patients who had agreed to participate in the study and had signed informed consent forms, nonetheless, became non-contactable before follow-up: $23 \mathrm{pa}-$ tients $(12.3 \%)$ were lost to follow-up before T2 and an additional 18 patients $(9.6 \%)$ lost contact before T3. These 41 lost patients were thus excluded from the longitudinal analysis. However, a comparison between responders and lost patients showed no statistically significant differences in baseline sociodemographic, alcohol intake-related, or other variables studied (online suppl. Table 1, see www.karger.com/doi/10.1159/000490046).

Half of our patient population had never undergone detoxification, whereas the remainder had been detoxified at least once. Taking into account responders only, the comparison between genders for age and alcohol intake-related variables did not show any differences (Table 1). On average, both males and females started drinking alcohol at the age of 18, began to abuse it 14 years later (age 32), and were admitted to a detoxification unit at about age 46. According to baseline AUDIT scores, almost the entire study sample showed high-risk drinking habits (zone IV), without any significant gender differences (Table 1).

The gender comparison of nonpharmacological treatment in responders did not find any statistically significant differences (Table 2). 
Table 1. Gender comparison of socio-demographic and clinical variables in responders at baseline $(n=146)$

\begin{tabular}{|c|c|c|c|c|}
\hline & \multicolumn{2}{|l|}{ Gender } & \multirow[t]{2}{*}{$\chi^{2}(\mathrm{DF})$} & \multirow[t]{2}{*}{$p$ value } \\
\hline & male, $n(\%)$ & female, $n(\%)$ & & \\
\hline \multicolumn{3}{|l|}{ Education, years } & $10.61(3)^{\mathrm{a}}$ & $0.009^{*}$ \\
\hline$<6$ & $7(7.0)$ & $2(4.3)$ & & \\
\hline $6-8$ & $59(59.0)$ & $18(39.1)$ & & \\
\hline $9-13$ & $33(33.0)$ & $21(45.6)$ & & \\
\hline$>13$ & $1(1.0)$ & $5(10.9)$ & & \\
\hline \multicolumn{3}{|l|}{ Marital status } & $14.73(3)^{\mathrm{a}}$ & $0.001^{*}$ \\
\hline Single & $37(37.0)$ & $10(21.7)$ & & \\
\hline Married/partnered & $21(21.0)$ & $24(52.2)$ & & \\
\hline Separated/divorced & $41(41.0)$ & $11(23.9)$ & & \\
\hline Widowed & $1(1.0)$ & $1(2.2)$ & & \\
\hline \multicolumn{3}{|l|}{ Living condition } & $22.19(4)^{\mathrm{a}}$ & $<0.001^{*}$ \\
\hline Alone & $30(30.0)$ & $10(21.7)$ & & \\
\hline With partner & $23(23.0)$ & $23(50.0)$ & & \\
\hline With parents & $40(40.0)$ & $9(19.6)$ & & \\
\hline With children & $0(0.0)$ & $4(8.7)$ & & \\
\hline With friends & $7(7.0)$ & $0(0.0)$ & & \\
\hline \multicolumn{3}{|l|}{ Employment } & $15.07(4)^{\mathrm{a}}$ & $0.003^{*}$ \\
\hline Employed & $39(39.0)$ & $23(50.0)$ & & \\
\hline Unemployed & $43(43.0)$ & $14(30.4)$ & & \\
\hline Disability pension & $10(10.0)$ & $0(0.0)$ & & \\
\hline Retired & $8(8.0)$ & $5(10.9)$ & & \\
\hline Housewife & $0(0.0)$ & $4(8.7)$ & & \\
\hline \multicolumn{3}{|l|}{ Previous detoxification } & $2.31(3)^{\mathrm{a}}$ & 0.520 \\
\hline 0 & $57(57.0)$ & $23(50.0)$ & & \\
\hline 1 & $27(27.0)$ & $18(39.1)$ & & \\
\hline 2 & $13(13.0)$ & $4(8.7)$ & & \\
\hline \multirow[t]{2}{*}{$>2$} & $3(3.0)$ & $1(2.2)$ & & \\
\hline & Mean (SD) & Mean (SD) & $\mathrm{U}(\mathrm{DF})$ & $p$ value \\
\hline Age, years & $46.9(8.9)$ & $46.0(10.8)$ & $0.56(144)^{\mathrm{b}}$ & 0.576 \\
\hline Age at onset of alcohol use, years & $18.0(5.7)$ & $18.0(7.5)$ & 2103.5 & 0.403 \\
\hline Age at onset of alcohol abuse, years & $32.5(11.4)$ & $32.1(11.1)$ & 2270.0 & 0.899 \\
\hline Length of hospitalization & $27.5(6.9)$ & $29.2(9.0)$ & 2107.5 & 0.415 \\
\hline $\begin{array}{l}\text { a Fisher's exact test. } \\
\text { b Students } t \text { test with DF. } \\
{ }^{*} \text { Statistically significant. }\end{array}$ & & & & \\
\hline
\end{tabular}

\section{Outcome of Detoxification}

At $\mathrm{T} 2,78(47.6 \%)$ of the 164 patients remaining in the study relapsed to drinking alcohol; they presented scores indicating various health risks, and there were no gender differences (Fisher's exact test $=2.90, p=0.419$ ). . According to the AUDIT scores, 54 patients (32.9\%) had high health risk (zone IV, 41 males vs. 13 females), 6 (3.7\%) had hazardous drinking (zone III, males vs. 2 females), 12 (7.3\%) were excessive drinkers (zone II, 7 males vs. 5 females), and 6 (3.7\%) had low health risk (zone 1, 3 males vs. 3 females). A total of 86 patients (52.4\%) maintained abstinence.
At T3, 78 (53.4\%) of the 146 patients remaining in the study relapsed to drinking alcohol, of which 14 (9.6\%) relapsed between $\mathrm{T} 2$ and $\mathrm{T} 3$. No gender differences in terms of AUDIT zone risk were found (Fisher's exact test $=1.72, p=0.709): 50$ patients $(34.2 \%)$ had high health risk (zone IV, 39 males vs. 11 females), 5 patients (3.4\%) had hazardous drinking (zone III, 3 males vs. 2 females), 6 patients (4.1\%) had excessive drinking (zone II, 5 males vs. 1 female), 17 patients (11.6\%) showed a low risk drinking (zone I, 10 males vs. 7 female). A total of 68 patients (46.6\%) were considered abstinent at T3. 
Table 2. Gender comparison of non-pharmacological treatment for responders $(n=146)$

\begin{tabular}{|c|c|c|c|c|}
\hline & \multicolumn{2}{|l|}{ Gender } & \multirow[t]{2}{*}{$\chi^{2}(\mathrm{DF})$} & \multirow[t]{2}{*}{$p$ value } \\
\hline & male, $n(\%)$ & female, $n(\%)$ & & \\
\hline Parent-training intervention, yes & $93(92.8)$ & $44(93.5)$ & $0.38(1)$ & 0.720 \\
\hline Short-term individual psychotherapy, yes & $95(94.4)$ & 43 (91.9) & $0.14(1)$ & 0.707 \\
\hline Group psychotherapy, yes & $91(89.6)$ & $42(88.7)$ & $0.01(1)$ & 1.000 \\
\hline Motivational enhancement therapy, yes & $90(88.8)$ & $42(87.0)$ & $0.06(1)$ & 1.000 \\
\hline Nutrition education, yes & $90(88.8)$ & $41(85.5)$ & $0.03(1)$ & 0.872 \\
\hline
\end{tabular}

\section{Longitudinal Analysis of Anxiety, Depression, and Alcohol Use}

Longitudinal analysis in 146 patients by using the generalized linear model revealed a significant within-subject effect for stages of assessment in state anxiety $(\mathrm{F}[2.6$, $\left.316.9]=19.27, p<0.001, \eta^{2} \mathrm{p}=0.14\right)$, trait anxiety $(\mathrm{F}[2.8$, 339.1] $\left.=97.12, p<0.001, \eta_{p}^{2}=0.44\right)$, and depression $\left(\mathrm{F}[2.8,343.3]=69.17, p<0.001, \eta^{2} \mathrm{p}=0.36\right)$. The main between-subject effect of gender was also significant for each of the 3 psychopathological dimensions (state anxiety, $\mathrm{F}[1,142]=11.42, p=0.001, \eta_{\mathrm{p}}^{2}=0.086$; trait anxiety, $\mathrm{F}[1,142]=9.28, p=0.003, \eta^{2} \mathrm{p}=0.07$; and depression, $\mathrm{F}[1$, $142]=15.33, p<0.001, \eta_{p}^{2}=0.11$; Table 3 ).

\section{Gender Differences in Anxiety, Depression, and}

Alcohol Use at Different Stages of Observation

At admission, females showed higher levels of state anxiety, trait anxiety, and depression, whereas their alcohol use severity did not differ from that of males (Table 3; Fig. 1-4). At discharge, levels of state and trait anxiety remained significantly higher in females, whereas no gender differences were observed for depression. At first follow-up, only depression levels were significantly higher in females than in males, whereas at the 12-month followup, both state anxiety and depression levels were higher in females than in males (Table 3 ).

\section{Gender Differences in Longitudinal Changes in}

Anxiety, Depression, and Alcohol Use

Both genders significantly improved between admission and discharge in state anxiety, trait anxiety, and depression (Table 4), although females showed a greater improvement in depression levels than males $(n=146$; time $\times$ gender T0-T1 contrast, $\mathrm{F}[1,142]=11.43, \eta_{\mathrm{p}}^{2}=$ $0.086, p=0.001)$. The improvement that was achieved in all of the clinical variables during detoxification remained significant in both genders within 12 months after discharge (Table 4, T0-T2 and T0-T3 mean differences in STAY-S, STAY-T and BDI). Moreover, no significant worsening in state anxiety was observed in either gender between $\mathrm{T} 1$ and $\mathrm{T} 2$ and between $\mathrm{T} 2$ and $\mathrm{T} 3$, whereas in males, trait anxiety significantly worsened between $\mathrm{T} 1$ and T2 (Table 4). Depression levels in both genders significantly worsened during the 12 months following discharge (Table 4, BDI T1-T3 mean differences), although only females had significantly worse symptoms 6 months after discharge (Table 4, BDI T1-T2 mean differences).

\section{Regression Analysis}

The Sidak-corrected univariate analysis estimation of baseline predictors revealed significant differences between relapsed and abstinent patients at both the T2 and T3 follow-ups. Therefore, 4 baseline variables (previous detoxifications, $\chi^{2}[1]=9.39, p=0.002$; number of previous detoxification, $\mathrm{U}[52]=184.5, p=0.001$; age of onset of alcohol use, $\mathrm{U}[52]=153.0, p<0.001$; and age of onset of alcohol abuse, $\mathrm{U}[52]=172.5, p=0.002$ ) were used as covariates in the logistic and linear regression models, which were used to evaluate the predictive value of anxiety and depression for relapse and drinking severity at T2 in female patients. Conversely, no baseline variable or nonpharmacological treatment was included as a covariate in the logistic and linear regression models for male patients. The logistic and linear models evaluating the predictive value of anxiety and depression for relapse and alcohol use severity at $\mathrm{T} 3$ included 3 baseline variables (previous detoxifications, $\chi^{2}[1]=17.76, p<0.001$; number of previous detoxifications, $\mathrm{U}[110]=643.0, p<0.001$; and living conditions, $\left.\chi^{2}[4]=13.12, p=0.004\right)$ for males and no baseline variable and no nonpharmacological treatment for females. Regarding the prediction of relapse and alcohol use severity at T2, only the linear regression model calculated for females reached statistical significance (adjusted $R^{2}=0.211$, $\mathrm{F}[11,36]=2.14, p=0.042$ ), indicating that predictors and covariates had no predictive value for alcohol use severity. Conversely, each of the 4 regression models, which were used to evaluate the predictive value of anxiety and depression for relapse and alcohol use severity at T3, reached sta- 
Table 3. Longitudinal variations of state anxiety, trait anxiety and depression $(n=146)$

\begin{tabular}{|c|c|c|c|c|c|c|c|}
\hline \multirow[t]{2}{*}{ Variable } & \multirow[t]{2}{*}{ Gender } & \multirow[t]{2}{*}{$\mathrm{I}$} & \multirow[t]{2}{*}{$\mathrm{J}$} & \multirow{2}{*}{$\begin{array}{l}\text { Mean differences } \\
(\mathrm{I}-\mathrm{J})\end{array}$} & \multicolumn{2}{|c|}{$95 \%$ CI for mean differences } & \multirow[t]{2}{*}{$p$ value } \\
\hline & & & & & inferior limit & superior limit & \\
\hline \multirow[t]{12}{*}{ STAY-S } & \multirow[t]{6}{*}{$\mathrm{M}$} & \multirow[t]{3}{*}{ T0 } & $\mathrm{T} 1$ & $5.177^{*}$ & 1.461 & 8.893 & 0.002 \\
\hline & & & $\mathrm{T} 2$ & $4.645^{*}$ & 0.902 & 8.389 & 0.007 \\
\hline & & & T3 & $3.929^{*}$ & 0.368 & 7.491 & 0.023 \\
\hline & & \multirow[t]{2}{*}{$\mathrm{T} 1$} & $\mathrm{~T} 2$ & -0.532 & -3.493 & 2.429 & 0.998 \\
\hline & & & $\mathrm{T} 3$ & -1.248 & -4.350 & 1.854 & 0.865 \\
\hline & & $\mathrm{T} 2$ & T3 & -0.716 & -2.903 & 1.471 & 0.945 \\
\hline & \multirow[t]{6}{*}{$\mathrm{F}$} & \multirow[t]{3}{*}{ T0 } & $\mathrm{T} 1$ & $8.449^{*}$ & 3.011 & 13.888 & $<0.001$ \\
\hline & & & $\mathrm{T} 2$ & $9.583^{*}$ & 4.104 & 15.063 & $<0.001$ \\
\hline & & & T3 & $8.013^{*}$ & 2.800 & 13.225 & $<0.001$ \\
\hline & & \multirow{2}{*}{$\mathrm{T} 1$} & $\mathrm{~T} 2$ & 1.134 & -3.200 & 5.468 & 0.981 \\
\hline & & & T3 & -0.437 & -4.977 & 4.103 & 1.000 \\
\hline & & $\mathrm{T} 2$ & T3 & -1.571 & -4.772 & 1.630 & 0.721 \\
\hline \multirow[t]{12}{*}{ STAY-T } & \multirow[t]{6}{*}{$\mathrm{M}$} & \multirow[t]{3}{*}{ T0 } & $\mathrm{T} 1$ & $17.412^{*}$ & 13.799 & 21.025 & $<0.001$ \\
\hline & & & $\mathrm{T} 2$ & $10.764^{*}$ & 6.753 & 14.774 & $<0.001$ \\
\hline & & & T3 & $10.634^{*}$ & 6.870 & 14.398 & $<0.001$ \\
\hline & & \multirow[t]{2}{*}{$\mathrm{T} 1$} & $\mathrm{~T} 2$ & $-6.648^{*}$ & -10.025 & -3.271 & $<0.001$ \\
\hline & & & T3 & $-6.777^{*}$ & -10.223 & -3.332 & $<0.001$ \\
\hline & & $\mathrm{T} 2$ & T3 & -0.129 & -2.821 & 2.562 & 1.000 \\
\hline & \multirow[t]{6}{*}{$\overline{\mathrm{F}}$} & \multirow[t]{3}{*}{ T0 } & $\mathrm{T} 1$ & $19.826^{*}$ & 14.537 & 25.114 & $<0.001$ \\
\hline & & & $\mathrm{T} 2$ & $17.381^{*}$ & 11.511 & 23.251 & $<0.001$ \\
\hline & & & $\mathrm{T} 3$ & $17.866^{*}$ & 12.357 & 23.375 & $<0.001$ \\
\hline & & $\mathrm{T} 1$ & $\mathrm{~T} 2$ & -2.444 & -7.387 & 2.498 & 0.714 \\
\hline & & & $\mathrm{T} 3$ & -1.960 & -7.003 & 3.084 & 0.883 \\
\hline & & $\mathrm{T} 2$ & T3 & 0.485 & -3.455 & 4.425 & 1.000 \\
\hline BDI & $\mathrm{M}$ & T0 & $\mathrm{T} 1$ & $9.069^{*}$ & 6.562 & 11.575 & $<0.001$ \\
\hline & & & $\mathrm{T} 2$ & $6.677^{*}$ & 3.771 & 9.583 & $<0.001$ \\
\hline & & & T3 & $6.219^{*}$ & 3.399 & 9.040 & $<.001$ \\
\hline & & $\mathrm{T} 1$ & $\mathrm{~T} 2$ & -2.391 & -5.033 & 0.250 & 0.097 \\
\hline & & & T3 & $-2.849^{*}$ & -5.147 & -0.552 & 0.007 \\
\hline & & $\mathrm{T} 2$ & T3 & -0.458 & -2.603 & 1.687 & 0.994 \\
\hline & $\mathrm{F}$ & T0 & $\mathrm{T} 1$ & $14.687^{*}$ & 11.018 & 18.356 & $<0.001$ \\
\hline & & & $\mathrm{T} 2$ & $9.553^{*}$ & 5.300 & 13.806 & $<0.001$ \\
\hline & & & T3 & $9.841^{*}$ & 5.713 & 13.969 & $<0.001$ \\
\hline & & $\mathrm{T} 1$ & $\mathrm{~T} 2$ & $-5.134^{*}$ & -9.000 & -1.268 & 0.003 \\
\hline & & & T3 & $-4.846^{*}$ & -8.209 & -1.483 & 0.001 \\
\hline & & $\mathrm{T} 2$ & T3 & 0.288 & -2.851 & 3.427 & 1.000 \\
\hline AUDIT & $\mathrm{M}$ & T0 & $\mathrm{T} 1$ & $26.998^{*}$ & 25.026 & 28.970 & $<0.001$ \\
\hline & & & $\mathrm{T} 2$ & $16.383^{*}$ & 13.554 & 19.213 & $<0.001$ \\
\hline & & & $\mathrm{T} 3$ & $16.435^{*}$ & 13.072 & 19.798 & $<0.001$ \\
\hline & & $\mathrm{T} 1$ & $\mathrm{~T} 2$ & $-10.615^{*}$ & -12.920 & -8.309 & $<0.001$ \\
\hline & & & T3 & $-10.562^{*}$ & -13.328 & -7.797 & $<0.001$ \\
\hline & & $\mathrm{T} 2$ & T3 & 0.052 & -3.346 & 3.450 & 1.000 \\
\hline & $\mathrm{F}$ & T0 & $\mathrm{T} 1$ & $28.141^{*}$ & 25.255 & 31.028 & $<0.001$ \\
\hline & & & $\mathrm{T} 2$ & $17.030^{*}$ & 12.889 & 21.172 & $<0.001$ \\
\hline & & & $\mathrm{T} 3$ & $19.919^{*}$ & 14.997 & 24.841 & $<0.001$ \\
\hline & & $\mathrm{T} 1$ & $\mathrm{~T} 2$ & $-11.111^{*}$ & -14.486 & -7.737 & $<0.001$ \\
\hline & & & T3 & $-8.222^{*}$ & -12.270 & -4.175 & $<0.001$ \\
\hline & & $\mathrm{T} 2$ & T3 & 2.889 & -2.085 & 7.863 & 0.545 \\
\hline
\end{tabular}

* Statistically significant. 


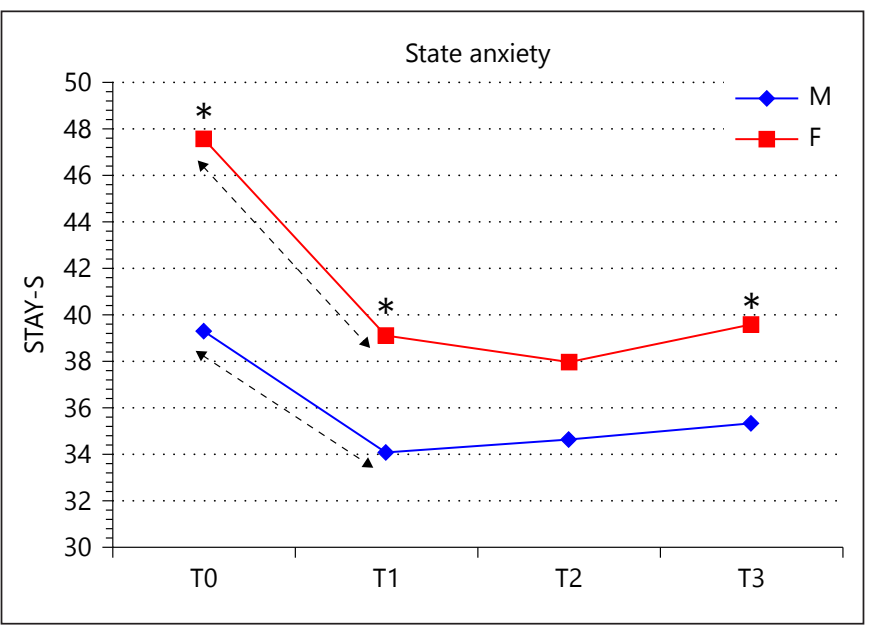

Fig. 1. Longitudinal variation of state anxiety. $<--->$ Statistically significant differences between stages. ${ }^{*}$ Statistically significant differences between genders.

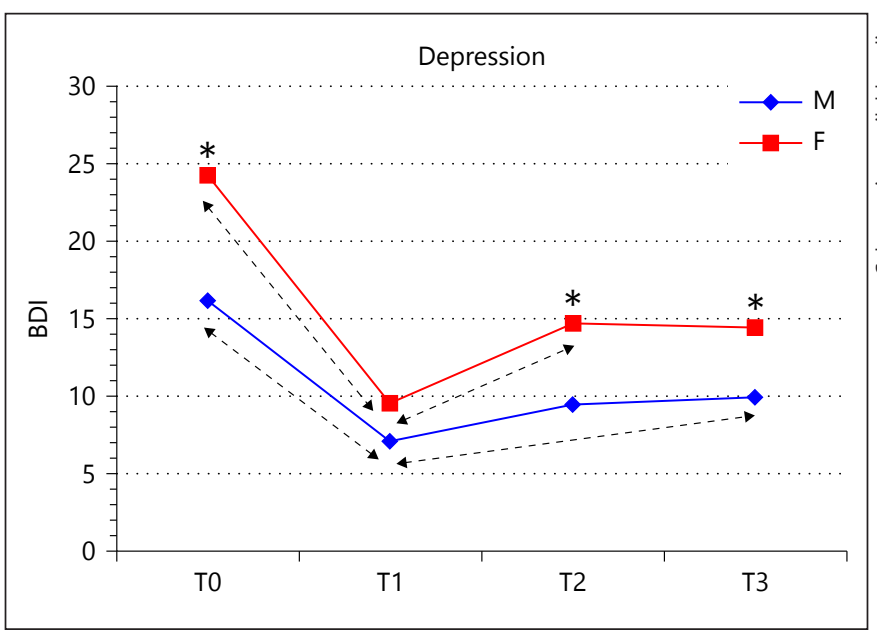

Fig. 3. Longitudinal variation of depression. $<--->$ Statistically significant differences between stages. ${ }^{*}$ Statistically significant differences between genders.

tistical significance. According to the logistic models, both STAY-S and STAY-T scores at T2 were significant predictors for relapse at T3 in male patients (STAY-S, OR 1.137, 95\% CI 1.012/1.278, $p=0.031$; STAY-T, OR 1.096, 95\% CI $1.018 / 1.179, p=0.014$; Model, Nagelkerke's $R^{2}=0.55$, $\left.\chi^{2}[10]=25, p=0.004\right)$, whereas only BDI scores at T2 were significant predictors for relapse in female patients (OR 0.545, 95\% CI 0.304/0.978, $p=0.042$; Model Nagelkerke's $\left.R^{2}=0.75, \chi^{2}[10]=30.9, p=0.001\right)$. The linear regression models showed that STAY-T scores at T2 had a significant predictive value for alcohol use severity in females at T3

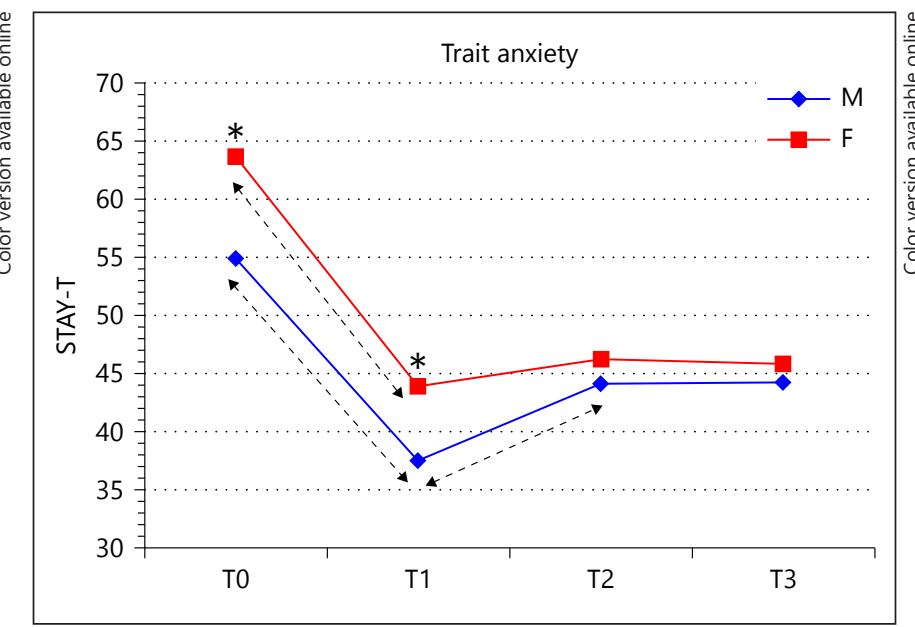

Fig. 2. Longitudinal variation of trait anxiety. $<--->$ Statistically significant differences between stages. ${ }^{*}$ Statistically significant differences between genders.

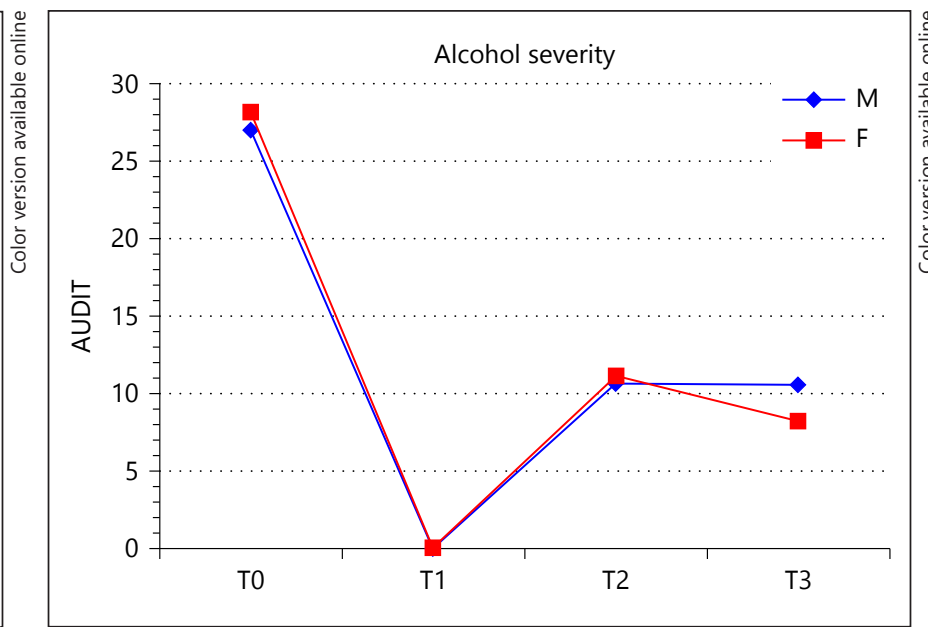

Fig. 4. Longitudinal variation of alcohol severity. <---> Statistically significant differences between stages. ${ }^{*}$ Statistically significant differences between genders.

$\left(\beta=0.30, \mathrm{t}[81]=2.24, p=0.27\right.$; Model, adjusted $R^{2}=0.041$, $\mathrm{F}[7,89]=1.59, p=0.042$ ), whereas no significant predictors were found for alcohol use severity in males (Model, adjusted $\left.R^{2}=0.340, \mathrm{~F}[13,72]=4.36, p<0.001\right)$.

\section{Discussion}

The present study on patients with AUD reveals a more severe and different clinical presentation in women than in men with regard to anxiety and depression at ad- 
Table 4. Gender comparison of state anxiety, trait anxiety, depression and alcohol use severity at different stages of observation $(n=146)$

\begin{tabular}{|c|c|c|c|c|c|c|c|c|}
\hline Variables & Stage & \multicolumn{2}{|l|}{ Males } & \multicolumn{2}{|c|}{ Females } & $\mathrm{F}(\mathrm{DF})$ & $p$ value & $\eta_{p}^{2}$ \\
\hline \multirow{3}{*}{ STAY-S } & $\mathrm{T} 1$ & 34.1 & $32.1-36.1$ & 39.1 & $36.1-42.1$ & $7.69(1,142)$ & 0.006 & 0.059 \\
\hline & $\mathrm{T} 2$ & 34.6 & $32.4-36.8$ & 38.0 & $34.7-41.2$ & $2.89(1,142)$ & 0.092 & 0.023 \\
\hline & $\mathrm{T} 3$ & 35.3 & $33.2-37.4$ & 39.5 & $36.4-42.6$ & $4.97(1,142)$ & 0.028 & 0.039 \\
\hline \multirow{3}{*}{ STAY-T } & $\mathrm{T} 1$ & 37.5 & $35.4-39.5$ & 43.8 & $40.8-46.8$ & $11.82(1,142)$ & 0.001 & 0.088 \\
\hline & $\mathrm{T} 2$ & 44.1 & $41.5-46.7$ & 46.3 & $42.4-50.1$ & $0.84(1,142)$ & 0.361 & 0.007 \\
\hline & T3 & 44.2 & $41.9-46.5$ & 45.8 & $42.4-49.1$ & $0.55(1,142)$ & 0.460 & 0.004 \\
\hline \multirow[t]{3}{*}{ BDI } & T0 & 16.1 & $14.0-18.3$ & 24.2 & $21.0-27.3$ & $17.51(1,142)$ & $<0.001$ & 0.126 \\
\hline & $\mathrm{T} 1$ & 7.1 & $5.6-8.5$ & 9.5 & $7.3-11.7$ & $3.43(1,142)$ & 0.066 & 0.027 \\
\hline & $\mathrm{T} 2$ & 9.5 & $7.4-11.5$ & 14.6 & $11.7-17.6$ & $8.13(1,142)$ & 0.005 & 0.062 \\
\hline \multirow{2}{*}{ AUDIT } & $\mathrm{T} 2$ & 10.6 & $8.9-12.3$ & 11.1 & $8.6-13.6$ & $0.11(1,142)$ & 0.746 & 0.001 \\
\hline & $\mathrm{T} 3$ & 10.6 & $8.5-12.6$ & 8.2 & $5.2-11.2$ & $1.63(1,142)$ & 0.204 & 0.013 \\
\hline
\end{tabular}

mission to an alcohol detoxification program. Consistent with previous studies $[9,15,19,20]$, females with AUD suffered from higher levels of state/trait anxiety and depression than males. Although there is strong evidence of more severe drinking behaviors in men (for a review see Erol \& Karpyak, 2015), according to this study, females did not differ from males in alcohol use severity at time of admission to the inpatient detoxification program. This could be explained by the fact that AUDs needing hospitalization for detoxification usually show a severe pattern of alcohol consumption, regardless of gender.

The alcohol detoxification program impacted anxiety and depression symptoms in both genders, but in contrast too previous findings [20], the reduction of depressive symptoms severity was significantly greater in females than in males. During the 12 months following discharge, levels of anxiety and depression increased without reaching those levels encountered at admission, with specific gender differences; that is, males seemed to present state and trait anxiety symptoms more quickly than females, whereas females were more prone to experiencing worsening depressive symptoms. This particular gender characterization of psychopathology after detoxification has not yet been explicitly recognized by other studies. According to the regression analysis performed in this study, both state and trait anxiety levels assessed 6 months after discharge predicted alcohol relapse in the following 6 months in males, whereas in females, depression levels at the 6-month follow-up predicted relapse 12 months after discharge. Therefore, in both genders, the psychopathological dimension showing the most significant aggravation at the 6-month follow-up (i.e., anxiety for males and depression for females) was a significant predictor of relapse at the 12-month follow-up. The relationship between negative affect, unpleasant mood states, depression, and alcohol use, as well as the predictive value of depression for alcohol relapse in female with AUD has been shown in previous reports $[15,16,18]$. Furthermore, other studies have demonstrated that this relationship between negative affect and relapse among women may be mediated by craving $[19,20,37]$. In the present study, the extent of relapse appeared to correlate with the recurrence of trait anxiety, as the severity of alcohol use behavior was predicted by the level of trait anxiety in relapsed females. There has been no evidence in the literature for trait or state anxiety being a predictor for alcohol relapse, although anxiety disorders have been recognized as conceivable predictors for relapse [14].

Taking into account the findings from our study on patients with AUD enrolled in an alcohol detoxification program, a gender-tailored approach that provides combined pharmacological and psychosocial intervention focused on state and trait anxiety for males and on depression/negative affect for females during the early and late post-discharge periods may be useful for reducing both individual risk of relapse and overall relapse rate, and for 
promoting long-term abstinence. A more straightforward implication of our findings in daily clinical practice is that the inclusion of specific assessment tools for depression and anxiety in follow-up examinations could help the specialist identify patients at high risk of alcohol relapse.

A noteworthy finding, not concerning the aims of the study, was that trait anxiety, relatively stable personality trait consisting of feeling of apprehension, tension, and increased activity of the autonomic nervous system [31], significantly decreased during admission in the whole sample but progressively increased in the months following admission in males only. This unexpected finding is partially consistent with that of Driessen et al. [38] who have already described changes in trait anxiety during detoxification, supporting a not well-recognized relationship between alcohol use/withdrawal and trait anxiety, which may involve the autonomic nervous system [39].

The main strengths of this study were the longitudinal approach, the evaluation of the predictive value of psychopathological levels for relapse and the long post-discharge observation time. Moreover, the relapse rate observed in our sample was comparable to that reported in previous studies $[4,14,40]$. However, the study does have some potential limitations. First, although the detoxification treatment was fixed and scheduled and all nonpharmacological treatments were taken into account, we cannot exclude the potential influence of both pharmacological and nonpharmacological treatments on psychopathological variables, especially during the follow-up period when data regarding treatments were lacking. Second, the partial responses at 2 follow-up appointments $(87.7 \%$ of 187 enrolled patients at 6 months; $78.1 \%$ at 12 months) might have led to a nonresponse bias, although no patients actually refused follow-up assessment, and nonresponders were lost patients who could no longer be contacted. Third, the time adjustment applied on AUDIT might affect its psychometric properties, but it allowed both a short and long-time follow-up assessments. Fourth, as the assessment of AUD, substance use disorders, and psychiatric disorders was made before the admission and thus outside the study design, our findings are so far from being considered generalizable. All evaluations were performed through self-rating instruments and questionnaires, and even if their psychometric proprieties and validity are well assessed, a clinician-administered test or interview could have improved the accuracy of the patient's assessment. Moreover, the collection of data concerning type and frequency of other addiction habits, especially tobacco smoking, could have improved the accuracy of predictors appraisal, reducing possible confounding effects.

Further studies are warranted to reach a more comprehensive evaluation of gender differences in AUD. A multicenter design could be considered in order to expand our knowledge on this subject. Moreover, these gender differences could be evaluated in other addictions, such as tobacco smoking or other substance use disorders, and in different clinical settings, such as both in outpatients and inpatients, taking into account also the effect of psychopharmacological treatments.

\section{Conclusions}

The findings of this study confirm the important role of gender differences in alcohol detoxification programs, with women showing higher levels of anxiety and depression before and after detoxification. The recurrence of anxiety and depressive symptoms in males and females 6 months after discharge predicted alcohol relapse at the 12-month follow-up. These findings provide support for a gender-tailored approach focusing on the assessment of specific symptoms in the early post-detoxification period to prevent alcohol relapse and promote long-term abstinence.

\section{Acknowledgment}

Researchers would like to thank all patients involved in the study for their valuable contribution.

\section{Disclosure Statement}

The authors declare that there are no potential conflicts of interest with respect to the research, authorship, or publication of this article.

\section{Funding Source}

This study has not received any funding support.

\section{Author Contribution}

F.O. and G.N. conceived and drafted the manuscript. P.V. and A.J.S. collected the data. F.O., G.N., and S.C. performed the statistical analysis. R.L.P. and L.O. participated in the design and coordination of the study. All authors read and approved of the final manuscript. 


\section{References}

1 American Psychiatric Association: Diagnostic and Statistical Manual of Mental Disorders, Fourth Edition, Revised: DSM-IV-TR ${ }^{\circledR}$. Washington, American Psychiatric Pub, 2000.

2 Regier DA, Farmer ME, Rae DS, Locke BZ, Keith SJ, Judd LL, et al: Comorbidity of mental disorders with alcohol and other drug abuse. Results from the Epidemiologic Catchment Area (ECA) Study. JAMA 1990;264: 2511-2518

3 Grant BF, Stinson FS, Dawson DA, Chou SP, Ruan WJ, Pickering RP: Co-occurrence of 12-month alcohol and drug use disorders and personality disorders in the United States: results from the National Epidemiologic Survey on Alcohol and Related Conditions. Arch Gen Psychiatry 2004;61:361-368.

4 Dawson DA, Grant BF, Stinson FS, Chou PS: Psychopathology associated with drinking and alcohol use disorders in the college and general adult populations. Drug Alcohol Depend 2005;77:139-150.

5 De Graaf R, Bijl RV, Spijker J, Beekman AT, Vollebergh WA: Temporal sequencing of lifetime mood disorders in relation to comorbid anxiety and substance use disorders - findings from the Netherlands Mental Health Survey and Incidence Study. Soc Psychiatry Psychiatr Epidemiol 2003;38:1-11.

6 Hasin DS, Stinson FS, Ogburn E, Grant BF: Prevalence, correlates, disability, and comorbidity of DSM-IV alcohol abuse and dependence in the United States: results from the National Epidemiologic Survey on Alcohol and Related Conditions. Arch Gen Psychiatry 2007;64:830-842.

7 Kessler RC, Nelson CB, McGonagle KA, Edlund MJ, Frank RG, Leaf PJ: The epidemiology of co-occurring addictive and mental disorders: implications for prevention and service utilization. Am J Orthopsychiatry 1996;66:17-31.

8 Swendsen JD, Merikangas KR, Canino GJ, Kessler RC, Rubio-Stipec M, Angst J: The comorbidity of alcoholism with anxiety and depressive disorders in four geographic communities. Compr Psychiatry 1998;39:176-184.

9 Conway KP, Compton W, Stinson FS, Grant BF: Lifetime comorbidity of DSM-IV mood and anxiety disorders and specific drug use disorders: results from the national epidemiologic survey on alcohol and related conditions. J Clin Psychiatry 2006;67:247-257.

10 Hesselbrock MN, Meyer RE, Keener JJ: Psychopathology in hospitalized alcoholics. Arch Gen Psychiatry 1985;42:1050-1055.

11 Ross HE: DSM-III-R alcohol abuse and dependence and psychiatric comorbidity in Ontario: results from the Mental Health Supplement to the Ontario Health Survey. Drug Alcohol Depend 1995;39:111-128.

12 Swendsen JD, Merikangas KR: The comorbidity of depression and substance use disorders. Clin Psychol Rev 2000;20:173-189.

13 Greenfield SF, Weiss RD, Muenz LR, Vagge LM, Kelly JF, Bello LR, et al: The effect of de- pression on return to drinking: a prospective study. Arch Gen Psychiatry 1998;55:259-265.

14 Schellekens AF, de Jong CA, Buitelaar JK, Verkes RJ: Co-morbid anxiety disorders predict early relapse after inpatient alcohol treatment. Eur Psychiatry 2015;30:128-136.

15 Erol A, Karpyak VM: Sex and gender-related differences in alcohol use and its consequences: contemporary knowledge and future research considerations. Drug Alcohol Depend 2015; 156:1-13.

16 Lau-Barraco C, Skewes MC, Stasiewicz PR: Gender differences in high-risk situations for drinking: are they mediated by depressive symptoms? Addict Behav 2009;34:68-74.

17 Rubin A, Stout RL, Longabaugh R: Gender differences in relapse situations. Addict Abingdon Engl 1996;91(suppl):S111-S120.

18 Abulseoud OA, Karpyak VM, Schneekloth T, Hall-Flavin DK, Loukianova LL, Geske JR, et al: A retrospective study of gender differences in depressive symptoms and risk of relapse in patients with alcohol dependence. Am J Addict 2013;22:437-442.

19 Karpyak VM, Biernacka JM, Geske JR, Abulseoud OA, Brunner MD, Chauhan M, et al: Gender-specific effects of comorbid depression and anxiety on the propensity to drink in negative emotional states. Addiction 2016;111:1366-1375.

20 Petit G, Luminet O, Cordovil de Sousa Uva M, Monhonval P, Leclercq S, Spilliaert Q, et al: Gender differences in affects and craving in alcohol-dependence: a study during alcohol detoxification. Alcohol Clin Exp Res 2017;41: 421-431.

21 WHO: The World Health Organization: WHO|Clinical guidelines for withdrawal management and treatment of drug dependence in closed settings. Geneva, World Health Organization, 2009. http://www.wpro. who.int/publications/docs/ClinicalGuidelines_forweb.pdf?ua=1.

22 Kosten TR, O'Connor PG: Management of drug and alcohol withdrawal. N Engl J Med 2003;348:1786-1795.

23 American Psychiatric Association: American Psychiatric Association Practice Guidelines for the Treatment of Psychiatric Disorders: Compendium 2006. Washington, American Psychiatric Pub, 2006.

24 Babor TF, de la Fuente JR, Saunders J, Grant M: The Alcohol Use Disorders Identification Test. Guidelines for Use in Primary Care, ed 2. Geneva, World Health Organization, 2001.

25 Spielberger C: Manual for the State-Trait Anxiety Inventory (STAI) (Form Y: Self-Evaluation Questionnaire). Redwood City, CA, Mind Garden, 1983.

26 Beck AT, Steer RA: Beck depression inventory: BDI. Psychological Corp., 1978.

27 Bohn MJ, Babor TF, Kranzler HR: The Alcohol Use Disorders Identification Test (AUDIT): validation of a screening instrument for use in medical settings. J Stud Alcohol 1995; 56:423-432.

28 Piccinelli M, Tessari E, Bortolomasi M, Piasere O, Semenzin M, Garzotto N, et al: Efficacy of the alcohol use disorders identification test as a screening tool for hazardous alcohol intake and related disorders in primary care: a validity study. BMJ 1997;314:420-424.

29 Saunders JB, Aasland OG, Babor TF, de la Fuente JR, Grant M: Development of the alcohol use disorders identification test (AUDIT): WHO collaborative project on early detection of persons with harmful alcohol consumption-II. Addiction 1993;88:791-804.

30 Donham GW, Ludenia K: Cross-validation of the State-Trait Anxiety Inventory with an alcoholic population. J Clin Psychol 1984;40: 629-631.

31 Spielberger CD, Pedrabissi L, Santinello M: STAI State-Trait Anxiety Inventory Forma Y: Manuale. Giunti OS Organizzazioni Speciali, 2012.

32 Lasa L, Ayuso-Mateos JL, Vázquez-Barquero JL, Díez-Manrique FJ, Dowrick CF: The use of the Beck Depression Inventory to screen for depression in the general population: a preliminary analysis. J Affect Disord 2000;57: 261-265.

33 Wang YP, Gorenstein C: Psychometric properties of the Beck Depression Inventory-II: a comprehensive review. Rev Bras Psiquiatr 1999 2013;35:416-431.

34 Montano A, Flebus G: Presentazione del Beck Depression Inventory - Seconda Edizione (BDI-II): conferma della struttura bifattoriale in un campione di popolazione italiana. Psicoter Cogn E Comportamentale 2006;12:67-82.

35 Dum M, Pickren J, Sobell LC, Sobell MB: Comparing the BDI-II and the PHQ-9 with outpatient substance abusers. Addict Behav 2008;33:381-387.

36 McPherson A, Martin CR: A narrative review of the Beck Depression Inventory (BDI) and implications for its use in an alcohol-dependent population. J Psychiatr Ment Health Nurs 2010;17:19-30.

37 Boykoff N, Schneekloth TD, Hall-Flavin D, Loukianova L, Karpyak VM, Stevens SR, et al: Gender differences in the relationship between depressive symptoms and cravings in alcoholism. Am J Addict 2010;19:352-356.

38 Driessen M, Meier S, Hill A, Wetterling T, Lange W, Junghanns K: The course of anxiety, depression and drinking behaviours after completed detoxification in alcoholics with and without comorbid anxiety and depressive disorders. Alcohol Alcohol Oxf 2001;36:249-255.

39 Johnson RH, Eisenhofer G, Lambie DG: The effects of acute and chronic ingestion of ethanol on the autonomic nervous system. Drug Alcohol Depend 1986;18:319-328.

40 Curran GM, Booth BM: Longitudinal changes in predictor profiles of abstinence from alcohol use among male veterans. Alcohol Clin Exp Res 1999;23:141-143. 